\title{
FORMAÇÃO LINGÜÍSTICA DO SELF E AÇÃO PEDAGÓGICA'
}

\author{
Cláudio Almir Dalbosco²
}

Resumo: $O$ artigo trata de alguns aspectos da teoria da ação de Mead relacionados com sua tese sobre a formação lingüístico-social do Self, procurando abordar desdobramentos pedagógicos. Concentra-se também em mostrar que o núcleo de sua teoria da ação repousa no conceito de ser humano como organismo agente que se constitui socialmente por meio da capacidade de empregar gestos e símbolos significantes.

Palavras-chave: Teoria da ação. Gestos. Símbolo. Significante. Psicologia do Self.

Processos pedagógicos relacionam-se com a formação de individualidades autônomas. Neles se descortinam, amplamente, o conteúdo e as dificuldades da dimensão formativo-educacional do ser humano. Buscar seu espaço, querer ser alguém com dignidade e reconhecimento social é um desejo de todo ser humano sensato. Tal busca está conectada a processos de aprendizagem e, por isso, questões sobre o que forma e educa o ser humano e como ele se educa e se forma a si mesmo em sua relação com os outros, com as instituições e com o meio ambiente são decisivas para a pedagogia e a filosofia. Nesse sentido, questões sobre a for-

1 Versão portuguesa da conferência "Die sprachliche Konstitution des Selbst (Self) und die pädagogische Handlung", proferida no Congresso Internacional Bildung und Moral, realizado na Universität Kassel (Alemanha) entre os dias 7 e 14 de julho de 2006. Agradeço à Deutschen Forschungsgemeinschaft (DFG - Sociedade Alemã de Pesquisa) pelo financiamento que tornou possível a apresentação dessa conferência. Este trabalho está vinculado ao projeto de pesquisa Teorias da Ação e Educação, à linha de pesquisa Fundamentos da Educação do Programa de Pós-Graduação em Educação e ao Núcleo de Pesquisa em Filosofia e Educação (Nupefe) da Universidade de Passo Fundo - RS. 
mação do si mesmo (Self/Selbst) também estão relacionadas com modos teóricos de sua legitimação.

A filosofia ocidental debruçou-se, historicamente, sobre o problema da formação do si mesmo, sem encontrar uma resposta definitiva. Em sua versão alemã moderna, tal problema foi justificado por meio do princípio da subjetividade, o qual se desdobrou, na filosofia de Kant, nos conceitos de consciência de si (Selbstbewusstsein) e consciência moral (Gewissen), e, na de Hegel, no conceito de espírito absoluto (Absoluter Geist). Esses conceitos, além de assumirem, no arcabouço teórico desses dois autores, a pretensão de ser o princípio unificador de seu sistema filosófico, serviram de base, quando desenvolvidos no campo pedagógico, para pensar a dimensão formativo-educacional do ser humano.

Apesar de todas as diferenças entre Kant e Hegel, críticos alemães contemporâneos ${ }^{3}$, influenciados pela linguistic turn, reconhecem um ponto comum no conceito de razão assumido por esses dois filósofos: ambos teriam identificado, grosso modo, o conteúdo racional da ação humana com o princípio da subjetividade e o teriam pensado de acordo com o modelo auto-reflexivo de um sujeito individual. Capaz de ação seria, nesse contexto, um sujeito pensante que constitui o mundo e a si mesmo na forma da representação de um objeto. Entre as objeções mais comuns dirigidas ao modelo reflexivo da consciência de si está a do seu caráter aporético: a formação do si mesmo seria pensada nos termos de uma estrutura reflexiva que só permitiria ao sujeito compreender a si mesmo mediante a condição de se tornar objeto de sua própria reflexão (Dalbosco, 2004, p. 161). Ora, se tal objeção procede, ela põe problemas não só no projeto moderno de justificação do si mesmo, por meio do conceito de subjetividade, como também nos desdobramentos pedagógicos que dele emergem. Como resultado, essa objeção coloca-se na raiz das mais diversas tentativas filosóficas contemporâneas de historicizar e contextualizar o conceito de razão.

No entanto, também se deve levar em consideração o fato de que muitas críticas dirigidas ao "projeto filosófico moderno", de modo especial, à filosofia de Kant e de Hegel, carecem, muitas vezes, de um trabalho exegético mais cauteloso, e é justamente essa ausência que permite aos críticos projetarem, retroativa e incisivamente, seu conceito de filosofia no âmbito argumentativo daqueles dois autores. Sendo assim, nelas estão implicados enormes dificuldades e problemas. O primeiro deles refere-se ao significado do conceito de subjetividade e da gama de conceitos que os filósofos modernos empregam como sinônimos ou, pelo menos, como muito próximos entre si - por exemplo, razão, mente, consciência e consciência de si. $O$ segundo diz respeito a saber até onde a inter-

3 Habermas e Tugendhat são exemplos conhecidos. 
pretação do conceito de subjetividade moderna corresponde, exegética e textualmente, à posição dos filósofos interpretados, e onde começam a criatividade e as livres interpretações. Por último, exige-se avaliar adequadamente as aporias e os limites oriundos da justificação filosófica, baseada no princípio da subjetividade, e ponderar sobre as soluções apresentadas pela crítica filosófica contemporânea.

Isso aponta, então, para um leque de exigências que só poderá cumprir-se por meio de um programa amplo e progressivo de investigação que não pode ser executado no âmbito de uma breve comunicação. Meus propósitos aqui são mais modestos. Sem ter de me posicionar diretamente sobre o conjunto dos problemas acima indicados, procuro tratar de alguns aspectos da teoria da ação de Mead que estão relacionados com sua tese da formação lingüístico-social do Self, para, em seguida, abordar desdobramentos pedagógicos. O núcleo de sua teoria da ação, que no momento me interessa, repousa no conceito de ser humano como um organismo agente que se constitui socialmente pelo emprego de gestos e símbolos significantes. Se o argumento de Mead mostrar-se, neste aspecto, minimamente plausível, dele também se poderão extrair indicações que talvez auxiliem no contorno de algumas das aporias oriundas do modelo reflexivo da consciência de si.

Um aspecto a ser considerado, inicialmente, diz respeito às razões que levam o pensamento de Mead, um autor provindo do âmbito filosófico anglo-saxônico, a exercer influência significativa no velho continente, de modo especial, em alguns filósofos alemães da segunda metade do século passado. A principal delas, e é a que me interessa agora, reside no fato de esse autor pensar o processo de socialização humana a partir da interação mediada simbolicamente sem, no entanto, secundarizar, com isso, os processos de racionalidade subjacentes à constituição da consciência de si. Sua filosofia pode ser tomada, nesse sentido, como exemplo paradigmático de um esforço que busca construir uma ponte entre os modelos reflexivos da consciência de si e as novas exigências teóricas oriundas do amplo movimento filosófico ligado a linguistic turn. No pensamento de Mead encontraríamos, portanto, um provocativo fio condutor que poderia nos inserir no âmbito de uma avaliação crítica da filosofia moderna, de modo particular, daquela diretamente vinculada ao princípio da subjetividade. Por outro, ao inserir-nos nesse contexto, sua filosofia está exposta a grandes problemas cuja capacidade de solução também precisa, ao menos, ser posta em questão. Formulando um desses problemas de modo mais preciso, trata-se de saber até que ponto seu conceito de organismo agente, gestual e simbólico, possui força reflexiva suficiente para enfrentar as aporias que resultam do modelo da consciência de si e, simultaneamente, apresentar uma justificação satisfatória à tese da constituição lingüístico-social do Self. Dessa questão depende também o fato de sua psicologia social, por um lado, poder ser transfor- 
mada em filosofia social e, por outro, enquanto tal, poder auxiliar na reflexão sobre a definição e a natureza dos processos pedagógicos.

Com essas considerações iniciais, ingresso agora no tema propriamente dito. $\mathrm{O}$ conceito de ação de Mead é herdeiro, em grande medida, de teorias psicológicas de sua época, as quais, por sua vez, deitam raízes nitidamente no pensamento filosófico moderno. Mead volta-se, criticamente, tanto contra a psicologia clássica da consciência como também contra a psicologia experimental, principalmente contra o behaviorismo de Watson.

A crítica de Watson à psicologia da consciência tornou-se instrutiva a Mead na medida em que liberou a psicologia das amarras de um procedimento introspectivo que, ao se limitar à análise dos "dados da consciência",enredou-se em inúmeras dificuldades. Sem precisarmos nos estender demasiadamente sobre o complexo problema da introspecção, basta, para o momento, oferecer uma caracterização simples: ela baseiase na noção de um conhecimento por consciência direta ou imediata, pretendendo ser, em sua versão rigorosa, um exame cuidadoso a ser feito sobre os conteúdos mentais. Ora, um limite principal de todo procedimento introspectivo, em suas mais diferentes versões, consiste no fato de querer transformar o mental e, com ele, a própria consciência em objeto de conhecimento, assentando esse seu procedimento sobre a tese de que é possível manter uma relação cognitiva com o metal.Tal relação é conquistada, no entanto, mediante a redução do mental a um objeto, e esse parece ser o preço a pagar pela postura filosófica dualista que sustenta o próprio procedimento introspeccionista. Há aqui, no mínimo, um duplo problema: o primeiro diz respeito ao fato de que nem todos os nossos estados mentais são coisas; o segundo, que nem sempre mantemos uma relação cognitiva com esses supostos objetos denominados estados mentais (Smith, 2005, p. 239).

Embora essas objeções formuladas ao introspeccionismo sejam, em sua grande parte, posteriores a Mead, ele já tinha certamente algumas delas presentes. Mas sua apreciação crítica geral contra tal procedimento não autoriza a conclusão de que Mead o tivesse desvalorizado por completo. Ao contrário disso, ele preserva aspectos do procedimento introspectivo, precisamente, para dar conta daqueles fenômenos inerentes a certas reações que não se expressam na forma de experiências da- 
das, como, por exemplo, as experiências passadas tornadas possíveis pela imaginação. Assim, afirma ele, no tocante à imaginação:"Semelhante experiência desempenha um papel, e um papel muito grande, em nossa percepção, em nossa conduta; e, no entanto, é uma experiência que só pode ser revelada pela introspecção" (Mead, 1992, pp. 9-10). ${ }^{4}$ Mas, por outro lado, formula uma objeção central contra o uso que a psicologia da consciência faz do procedimento introspectivo: baseando-se na premissa geral que opõe, dicotomicamente, consciência e matéria, mente e corpo, tal psicologia reduz, segundo Mead, o acesso aos "dados da consciência" a uma atitude introspectiva, procurando explicar também o que está fora da consciência com base em tal atitude. Com linguagem atualizada, diríamos hoje que a psicologia da consciência provocou uma espécie de "objetificação" dos predicados mentais e uma "mentalização" dos predicados físicos. A introspecção torna-se, portanto, aos olhos de Mead, bastante ineficaz, porque deixa de lado o aspecto dinâmico inerente ao conceito de organismo agente, concentrando-se somente nos aspectos estáticos referidos à consciência como estado ou substância, vertendoos contra o mundo exterior.

É nesse contexto mais geral que também se deixa esclarecer a importância da crítica de Watson à psicologia da consciência. A partir de tal crítica, Watson estabelece o comportamento humano como novo objeto da psicologia, derivando seu conteúdo da premissa metodológica de análise do comportamento mediante as variantes externas observáveis que o determinam. Mas Mead não o acompanha inteiramente nesse passo, pois critica o reducionismo nele subjacente, afirmando que tal procedimento não consegue mais dar conta da intencionalidade da ação humana. Contra isso, ele objeta a idéia de que há aspectos subjetivos indispensáveis à constituição da ação humana e que não necessariamente precisam ser vistos na forma de estados interiores ou de mundo subjetivo em um sentido psicologista, mas, sim, como parte de um organismo que interage, lingüisticamente, consigo mesmo e com o meio. Contra Watson ele afirma que "a ação externa que observamos constitui uma parte do processo que se tem iniciado no interior" (Mead, 1992, p. 5). A ação sintetiza, nesse sentido, tanto certas características das coisas como certas experiências do ser humano, pois dentro da "ação mesma existe um campo que não é externo, senão que pertence à ação e há características dessa conduta orgânica interna que se mostram em nossas atitudes, especialmente nas relacionadas com a fala" (Mead, 1992, p.5).

Sua crítica a Watson permite-o resgatar a dimensão interna da ação, interpretando-a agora, no contexto de sua psicologia social, não mais

4 As traduções do texto citado de Mead são de minha autoria, cotejadas com as edições espanhola e alemã de Mind, Self \& Society. 
como um simples estado de consciência, mas como ação simbólica manifestada, em sua primeira fase, pelo gesto e, posteriormente, pelo símbolo significante. Este é um passo metodológico importante de sua psicologia social, que lhe permitirá analisar a dupla dimensão constitutiva da ação humana, a gestual e a simbólica, diferenciando-as entre si e atribuindo-Ihes papéis específicos no processo de constituição do Selfe, num sentido mais amplo, da própria socialização humana.

Com essa breve indicação sobre o modo como Mead se posiciona em relação a pontos importantes do pensamento psicológico de sua época, gostaria de dar um passo adiante na exposição e sinalizar alguns aspectos que possibilitam transformar o conceito de psicologia social em uma teoria social em sentido filosófico, para, posteriormente, poder analisar os desdobramentos pedagógicos atinentes.

Posto o problema nesses termos, ele nos auxilia a mostrar a importância do pensamento de Mead como exemplo de um trabalho teórico interdisciplinar, uma vez que sua abordagem dos problemas exige a imbricação e o constante paralelo analógico entre diferentes áreas do conhecimento humano. As dificuldades que se apresentam a esse trabalho referem-se a saber o que significa uma teoria filosófica do social e em que sentido a psicologia social de Mead aponta nessa direção. ${ }^{5}$

Vista em sentido amplo e atual, uma teoria filosófica do social precisa oferecer ao menos uma articulação coerente entre os conceitos de ação, linguagem, racionalidade e sociedade e, do ponto de vista metodológico, apresentar, satisfatoriamente, uma análise da imbricação entre ação individual e processo social. Embora Mead não ofereça um tratamento sistemático - e este é um obstáculo evidente ao propósito de ver seu projeto já previamente como uma teoria filosófica da sociedade -, há fortes indicações em seus argumentos que apontam na direção de uma teoria filosófica do social. Penso que dois deles são decisivos: o primeiro reside no conceito de ação social, formulado pelo autor, que, definido como interação mediada simbolicamente, exige o nexo estreito entre linguagem e racionalidade; o segundo, conectado com o primeiro, em pensar a constituição do Self em termos de processo social mediado simbolicamente. Se estes são argumentos decisivos para que sua psicologia social possa ser interpretada como filosofia social, eles

5 Talvez, por isso, não seria aconselhável, como fazem Tugendhat e Habermas, interpretar Mind, Self \& Society já como uma filosofia social sem antes discutir os problemas implicados na passagem da psicologia social à filosofia social, pois o que Mead tem em mente é, inicialmente, o projeto de fundação de uma psicologia social. 
não deixam de conter inúmeras dificuldades, cuja principal reside, certamente, na justificativa, fornecida por Mead, dos conceitos de indivíduo e sociedade ainda baseada em certos aspectos da teoria behaviorista da ação humana.

Considerando isso, é possível balizar uma aproximação entre psicologia social e teoria filosófica da sociedade, sinalizando, ao mesmo tempo, para um desdobramento pedagógico. A crítica da psicologia experimental à psicologia da consciência contribuiu decisivamente à "dessubstancialização" da consciência, liberando a teoria de "amarras metafísicas" e colocando os problemas de justificação inteiramente no plano racional do universo sociolingüístico das relações humanas. O problema de tal crítica, em sua vertente experimental-comportamentalista, é que ela encurtou de tal forma o conceito de experiência humana (ação humana) que terminou por reduzi-lo somente aos seus aspectos observáveis. Ou seja, inaceitável tornou-se para Mead, em última instância, a própria teoria verificacionista do significado do behaviorismo ortodoxo, a qual estava amparada na premissa de que o significado cognitivo do proferimento lingüístico dependia de suas condições de verificação empírica. Ora, foi justamente essa teoria verificacionista que legitimou a redução levada adiante pelo behaviorismo do significado de todo o amplo domínio daquilo que se denominou mental à esfera do comportamento observável.

O primeiro passo da psicologia social, enquanto teoria filosófica do social - incorporando o avanço da psicologia experimental, mas rejeitando firmemente o objetivismo ingênuo resultante de sua teoria reducionista do significado -, consiste em ampliar novamente o conceito de experiência humana e em fazê-lo inserindo-o no conceito de organismo. Transformada em teoria filosófica do social, a psicologia traz em seu bojo a exigência metodológica de investigar o nexo entre ação individual e processo social, amparando-se na tese de que a própria ação individual já é, desde seu início, ação social e, mais ainda, de que a ação social com significado é aquela produzida lingüisticamente por meio de um tensão inesgotável entre interior e exterior. Diante desse novo quadro, compete à psicologia social transformada em filosofia social investigar o processo social de constituição da ação,"no qual está inserido qualquer grupo dado de indivíduos humanos e do qual dependem a existência e o desenvolvimento da mente, do Self e da consciência de si dos envolvidos" (Mead, 1992, p. 82).

Desse modo, a psicologia social, como teoria filosófica da sociedade, auxilia-nos a visualizar o significado filosófico que a crítica de Mead assume em relação não só às posturas teóricas da psicologia de sua época, como também à tradição filosófica moderna, especialmente àquela tradição que se ampara no modelo reflexivo da consciência de si (Selbstbewusstsein). Nesse sentido, seu trabalho pode ser tomado como 
instaurador de um novo ponto de partida para a argumentação filosófica, buscando livrá-la daquelas aporias inerentes à "metafísica da subjetividade".6 Ao tomar o conceito de ação simbólica como ponto de partida para compreender o processo de socialização humana, as análises de Mead evidenciam, por um lado, mediante sua crítica à psicologia da consciência, o procedimento subjetivo-objetualista que está subjacente à argumentação filosófica baseada no princípio da subjetividade. Por outro, confrontando-se criticamente com a psicologia experimental, elas também revelam a estreiteza do procedimento científico baseado no princípio de restrição do comportamento humano aos seus aspectos meramente observáveis.

Em síntese, o objetualismo subjacente às duas posturas deixa-se formular do seguinte modo: ao se referir a si mesmo de modo cognoscente ou a ser determinado pelos estímulos externos, o sujeito constitui seu Self somente na medida em que o apreende como objeto. Isto é, qualquer uma das duas posturas acima termina por justificar o processo de constituição do Self nos moldes de uma relação dicotômica entre sujeito e objeto: concebido em sua estrutura cognitiva como conhecimento ou em sua estrutura comportamental como ação, o Self só consegue apreender a si mesmo e apreender o mundo que está a sua volta mediante a condição de ter de tomar a si mesmo como objeto. Se a argumentação procede, ela nos autoriza a concluir que tanto psicologia da consciência como psicologia experimental, por ainda estarem inseridas, de modo geral, nas premissas da subjetividade moderna, seriam portadoras de um conceito de razão baseado no modelo de relação de um sujeito solitário com algo no mundo objetivo a ser por ele representado e manipulado (Habermas, 1995a, p. 525).

Como Mead pensa a constituição do Self por meio do caminho da interação mediada simbolicamente, sua contribuição deixa-se ver como uma tentativa de tratar das aporias inerentes ao modelo reflexivo da consciência de si, oriundas da tradição do idealismo alemão. Sua produtividade reside no enfoque do sujeito falante e, com ele, da postura performativa de inclusão de uma segunda pessoa, rompendo com o enfoque subjetivo da primeira pessoa, próprio à psicologia da consciência, e com o enfoque descritivo-objetivante da terceira pessoa, próprio à psicologia experimental. Entre os contemporâneos, e como crítica ao pensamento objetualista, Mead seria, então, o primeiro a refletir sobre o modelo intersubjetivo do Self produzido socialmente (Habermas, 1992, p. 209). Como se pode obser-

6 As análises tanto de Tugendhat (1997, pp. 245-292) como de Habermas (1992, pp. 187-241; 1995, pp.7-68) vêem no pensamento de Mead o início de um novo paradigma filosófico. Também ofereço uma interpretação nessa perspectiva em Dalbosco (2004, pp. 155-181). 
var, com esses raciocínios depositam-se grandes expectativas em sua psicologia social transformada em teoria filosófica da sociedade.

\section{IV}

No entanto, tornar a psicologia social de Mead uma teoria filosófica da sociedade depende, em grande medida, de uma justificação adequada do conceito de organismo que age gestual e simbolicamente e, portanto, depende de seu próprio conceito de linguagem. Também muitos problemas estão implicados aí. Um deles - talvez o mais complicado, já indicado por, entre outros autores, Habermas e Tugendhat ${ }^{7}$ - consiste na ausência de uma teoria sistemática do significado. Isto é, segundo esses dois autores, Mead não teria desenvolvido uma teoria do significado que pudesse sustentar sistematicamente suas intuições gerais sobre o papel socializador desempenhado pela linguagem humana. Um outro, derivado imanentemente da própria argumentação de Mead, refere-se ao fato de ele intercalar entre os conceitos de gesto e símbolo a exposição de outros conceitos, como gesto vocal, imitação e significação. Isso não só dificulta a compreensão dos conceitos de gesto e símbolo, como põe obstáculos à sua diferenciação e à compreensão do sentido e do papel que esses dois conceitos desempenham no processo de socialização humana.

Antes de tratar dos conceitos de gesto e símbolo, preciso fazer uma observação sobre o conceito geral de linguagem assumido por Mead. Ele se insere no seu conceito mais amplo de ação, cuja base teórica se origina de seu confronto crítico com diferentes posturas intelectuais de sua época. $O$ confronto com essas posições serve-lhe para balizar seu enfoque evolutivo-comportamentalista de linguagem. A tese geral de Mead é a de que a linguagem humana desempenha papel decisivo na constituição da conduta racional do Self.Portanto, segundo ele, a mente, em sentido mais restrito, e o próprio organismo agente, em sentido mais

7 Embora eu não vá me ater a essas críticas, gostaria de resumir o núcleo delas formulado por esses dois autores e já indicado por mim em outra oportunidade (Dalbosco, 2004, p. 163 e p. 165, respectivamente). Segundo Habermas, os limites mais evidentes do conceito de linguagem de Mead consistem no seguinte: a) distinção insatisfatória entre ação mediada por símbolos e ação mediada por normas, passando diretamente de uma para outra sem tratar da dimensão proposicional da linguagem; b) não percebeu adequadamente o papel desempenhado pelo entendimento lingüístico como medium da interação social e; c) vinculado a isso, não analisa adequadamente o papel desempenhado pela linguagem enquanto meio do entendimento humano-social. Tugendhat, por sua vez, aponta para os seguintes limites do conceito de linguagem de Mead: a) não trata da reação peculiar sim/não e, com ela, da diferença entre as proposições assertivas e imperativas; b) não trata dos termos singulares que estavam ausentes na linguagem de sinais, mas presentes nas orações características da linguagem simbólica. 
amplo, são emergentes sociais constituídos lingüisticamente, e a linguagem - em sua dimensão gestual e simbólica - proporciona o mecanismo geral para tal emergência. A linguagem é, nesse sentido, um fenômeno objetivo de interação que emerge dentro de um grupo social, constituindo-se, também, em fator decisivo da organização e do controle da ação humana.

Visto a partir desse enfoque, o gesto constitui o nível mais elementar da ação de um organismo. Seu mecanismo restringe-se a provocar estímulos, mas não permite a internalização de seu significado e nem do significado das reações que tal estímulo provocou nos outros indivíduos envolvidos. Esse limite intrínseco à sua natureza impede-o de se transformar em símbolo significante. No entanto, apesar de tal limite, o gesto já sinaliza claramente etapas posteriores da mesma ação que se inicia com ele, constituindo-se assim em elo importante da grande cadeia que forma a tessitura complexa das relações entre integrantes de uma mesma comunidade social.

O gesto contém uma dimensão comunicativa mínima. Convertido em estímulo para outro indivíduo, sempre provocará uma reação nele, pondo os indivíduos em contato entre si, criando expectativas e moldando as mais diferentes formas de reação a serem adotadas. Como forma elementar de comunicação, o gesto impele à ação; no entanto, considerando os exemplos empregados por Mead para caracterizá-la, trata-se ainda de uma ação que se volta prioritariamente à autoconservação de quem a profere, dizendo respeito, portanto, a uma reação instintiva que está diretamente ligada à supressão de necessidades básicas e imediatas de seus portadores. Por isso, mesmo apresentando um certo nível de comunicação, a ação gestual não pode ser considerada uma linguagem propriamente dita, porque nela os significados ainda não estão na"mente".Ela caracteriza, pois, o âmbito de ação de um indivíduo biológico que, agindo por sinais, não possui a capacidade de internalizar os significados veiculados por tais sinais. Para Mead está claro, nesse sentido, que um indivíduo biológico que age gestualmente ainda não é portador de uma mente e, por isso, não é um indivíduo que age comunicativamente de modo consciente. Sendo assim, se a linguagem humana permanecesse somente no nível gestual, ela não poderia dar origem ao Self.

Precisamos analisar com mais cuidado o que significa a tese de que o gesto já representa um certo nível de comunicação, embora não seja ainda uma comunicação consciente. Mead procura esclarecê-la ao afirmar que o gesto é uma forma de conversação, ocorrendo por sinais, sem ser uma linguagem articulada. A conversação de gestos não é uma linguagem articulada, assim reza seu argumento, porque não pode assumir a condição de produzir uma significação universal para todos os indivíduos e, por isso, não pode provocar neles uma reação idêntica. Mead compreende o gesto como atitude cooperativa entre animais e seres huma- 
nos que não implica um significado idêntico em seu uso. Como exemplo, ele reporta-se, freqüentemente, à sociedade de formigas e à de abelhas. Esses insetos desenvolvem um nível de comunicação que torna possível uma atitude cooperativa, mas tal comunicação não assume um significado idêntico que pudesse ser traduzido em termos de símbolo e que também pudesse se reverter, por exemplo, em uma insubordinação coletiva dos subalternos em relação a ordens superiores. Isso explica o fato de que abelhas e formigas continuam a trabalhar geração após geração, acatando passivamente ordens superiores. Nessa situação, comunicando-se mutuamente, só por meio do emprego gestual, elas não atingem o nível propriamente dito da cultura e da educação. Continuam agindo instintivamente, geração após geração, sem poder romper com o ambiente natural e minimamente social que lhes é dado.

Com isso, fica caracterizado também que o gesto é uma ferramenta por meio da qual indivíduos reagem entre si. Ele é um elemento altamente importante da organização da ação social desses indivíduos e assume tal forma porque se desenvolve através do mecanismo estímuloreação, provocando neles adaptação e readaptação. Assim, afirma Mead: "O jogo recíproco se leva a cabo de modo que os gestos executem suas funções provocando reações nos outros e essas reações se convertam, por sua vez, em estímulos à readaptação, até que o ato social mesmo possa ser efetuado" (Mead, 1992, p. 44).

Do exposto até aqui, podemos afirmar que a ação gestual constitui-se em um nível elementar de linguagem que desempenha o papel indispensável de socialização adaptativa do indivíduo, desencadeando uma função integrativa mínima sem a qual não poderia existir socialização entre as espécies de animais superiores. Embora não se constitua em linguagem articulada e não apresente um nível complexo de racionalidade, o gesto, por ser constitutivo de um certo nível de ação social, mostra o fato de que seus significados mínimos não são meramente subjetivos, no sentido de serem somente privados e mentais, mas são expressões objetivas de situações sociais. Ora, é essa idéia que está na base do enfoque evolutivo-comportamentalista de linguagem que permite a Mead voltar-se contra uma concepção mentalista e, portanto, contra o conceito de linguagem que se origina da "filosofia do sujeito."Também é como forma elementar de ação social que o gesto prepara, no contexto da linguagem humana, o surgimento do símbolo significante.

\section{V}

Se a exposição do conceito de gesto deixa claro seu papel no surgimento da sociabilidade animal, evidencia, ao mesmo tempo, o limite desse conceito na constituição da sociabilidade especificamente hu- 
mana. Para que esta possa surgir e se configurar em sua inteireza, é necessário que a linguagem assuma forma simbólica. Mead esclarece essa transformação ao introduzir o conceito de símbolo significante. Sua tese geral é a de que o símbolo significante oportuniza o surgimento da consciência de si e, portanto, a aparição do Self. Seu aparecimento se torna possível porque a ação humana apresenta, em seu nível simbólico, uma especificidade em relação à ação gestual: seu dinamismo possibilita, primeiro, que um indivíduo provoque em si mesmo uma reação semelhante à que a ação provocou no outro indivíduo, permitindo-lhe adotar a atitude do outro como mecanismo de coordenação de sua própria ação; segundo, que transforme sua própria reação em um novo estímulo à continuidade da ação.

Para esclarecer o símbolo significante e estabelecer a diferença entre ele e o gesto, Mead introduz o conceito de gesto vocal. Como um fenômeno imitativo, o gesto vocal é uma ação que apresenta ao sujeito agente a capacidade de adoção da atitude do outro, mas agora não mais de forma meramente mecânica e instintiva, como estava representada no gesto. Ao atingir o estágio do gesto vocal, a ação humana desenvolve uma capacidade mínima de escuta que lhe torna possível ver a si mesma por meio da internalização de sons provindos do exterior e, principalmente, pronunciados por seus semelhantes. Como exemplifica Mead, o ser humano não pode ver seu próprio semblante, a não ser quando está diante de um espelho, mas pode ver a si mesmo por meio da escuta de seu próprio gesto vocal. O gesto vocal significa, então, nesse contexto, um nível elevado de intercâmbio de sons que ultrapassa o âmbito da reação imediata e instintiva e revela um estágio mínimo de racionalidade que a linguagem passa a assumir, deixando de ser tão somente uma espécie de imagem refletida no espelho. Ora, é essa capacidade surgida com o gesto vocal que está na origem de um nível mais evoluído de interação humana, indispensável à constituição posterior de sofisticados processos sociais, os quais darão forma, por sua vez, à estrutura complexa do Self.

Mas gesto vocal não é ainda símbolo significante. Embora o argumento de Mead vacile constantemente, uma reconstrução atenta pode traçar a diferença entre o gesto vocal e o símbolo significante nos seguintes termos: com o emprego de gestos vocais, o indivíduo está constantemente provocando em si mesmo a reação que despertou nas outras pessoas e o faz de tal modo que incorpora em sua ação a atitude do outro. Esse mecanismo recebe, no entanto, no âmbito do símbolo significante, um acréscimo importante no sentido de que a reação que provoca em si mesmo se transforma em um novo estímulo à continuidade da ação. $O$ fato de a reação se constituir em um novo estímulo é o aspecto decisivo do emprego significativo de símbolos que permite romper com o mecanicismo do gesto e conceber a linguagem humana como 
uma cadeia de ações, na qual o sentido manifesto em uma ação desencadeia outra.

O símbolo significante nada mais é do que a capacidade de internalização dos gestos vocais e a sua posterior externalização com novos significados. Adquire uma base de significação comum que proporciona, respectivamente, atitude semelhante no indivíduo que executa uma ação e no que reage a ela e permite que a reação se transforme em novo estímulo. Somente graças a esse processo é que o indivíduo pode internalizar ou ter consciência de sua ação e suas significações. Somente nesse contexto é que o estímulo se torna significante, pois é pressupondo a identidade comum do símbolo que um indivíduo se torna capaz de dizer algo com sentido e de ser levado a sério por alguém. $O$ "significante" que adjetiva o substantivo "símbolo" revela o caráter reflexivo da linguagem, isto é, sua capacidade de voltar-se sobre si mesma e, além de provocar no falante o mesmo tipo de reação que sua fala provocou no ouvinte, também transformar sua própria reação em estímulo para uma outra reação. "O peculiar aos símbolos significantes é que o indivíduo reage aos seus próprios estímulos do mesmo modo como reagem outras pessoas" (Mead, 1992, p. 67).

O resultado acima me permite antecipar agora, provisoriamente, um aspecto central da constituição do Self: se a consciência não pode mais ser vista como um estado, pois é agora abordada como um processo que se evidencia em ato e ação, também uma teoria moderna do Self não pode mais concebê-lo como um estado subjetivo cuja ação é dirigida por um comando interno localizado em algum lugar no sistema nervoso central e nem só como resultado da influência de fatores externos, que a determinariam previamente. O Self é, desse modo, desde o princípio, ação ou, melhor dito, é constituído desde o início pelo modo como o organismo interage lingüisticamente consigo mesmo e com o meio. Ele é constituído, portanto, por um processo sociolingüístico de internalização e externalização. Formado por tal dinâmica, o Self precisa apresentar uma instância interna capaz de elaborar o mundo exterior que chega até ele e, ao mesmo tempo, efetivar-se objetivamente no processo social. Ele precisa apresentar uma dupla dimensão, formada socialmente, para que possa exercer poder constitutivo sobre si mesmo e sobre o que está a sua volta. Sua explicação, levada adiante nesses termos, seria capaz de evitar, segundo Mead, a mecanicidade no modo de pensar a ação humana, modo este que é inerente à psicologia da consciência e ao behaviorismo experimental. Como esclarece Mead, na terceira parte de Mind, Self \& Society, essa dupla dimensão do Self é formada pelo / e pelo Me. 
Depois desta breve reconstrução, gostaria de me encaminhar para a conclusão, conectando o exposto a uma problemática explicitamente pedagógica.Tal problemática deriva, de modo mais preciso, da crítica que a psicologia social transformada em crítica filosófica da sociedade pode fazer tanto à psicologia da consciência quanto à psicologia experimental. O que a exposição permite reter, negativamente, contra o núcleo pedagógico da psicologia da consciência é a tese de que o processo pedagógico não pode se concentrar tão somente em querer desenvolver as potencialidades internas do educando - ao extrair o sentido formativo do ser humano só a partir de seu interior -, uma vez que tal psicologia repousa num pressuposto epistemológico insuficiente, o qual se propõe explicar o externo somente por meio do acesso introspectivo ao interno. Contra a psicologia experimental, por sua vez, tal tese opõe a idéia de que o processo formativo-educacional não ocorre só como reação aos estímulos originados externamente, mas que deve levar em consideração a constituição subjetiva do sujeito agente. Aqui valeria, de modo geral, a crítica já feita por Kant ao empirismo, séculos antes, a saber, se todo o conhecimento começa (fängt an) com a experiência, nem todo ele se origina (entspringt) da experiência. Assim, do exposto até aqui podemos formular, provisoriamente, o seguinte resultado para o campo pedagógico: Pelo fato de o processo pedagógico desencadear-se entre sujeitos falantes que se comunicam entre si e consigo mesmos, ele deve incorporar aquela capacidade inerente à ação humano-lingüística de provocar no próprio sujeito falante, de modo semelhante, o tipo de reação que sua fala provoca em seu interlocutor e, além disso, de poder transformar sua própria reação em um novo estímulo à continuidade de sua ação. Apesar da terminologia ainda demasiadamente behaviorista, essa idéia contém um alcance metodológico-pedagógico nítido, o qual reside na exigência feita de antemão a todos os envolvidos na relação pedagógica, e não só a um deles, por exemplo, não só ao filho ou ao aluno, mas também ao pai e ao professor, de se colocarem como sujeitos ouvintes na situação. ${ }^{8}$ Tal alcance conduz à crítica da postura do observador distante, que fala sobre algo e sobre os outros, mas sempre se colocando de fora da situação. Essa me parece ser uma exigência central posta à ação pedagógica, quando pensada em termos de uma teoria simbólica da ação humana.

Por outro lado, a breve exposição dos conceitos de gesto e símbolo permite visualizar, provisoriamente, um outro desdobramento pedagógico. Considerando o caráter eminentemente mecânico e instintivo da ação gestual, dela não pode emergir o que se denomina cultura no senti-

8 Abrir-se-ia aqui uma perspectiva teórica que possibilitaria aproximar o interacionismo simbólico de Mead da hermenêutica contemporânea, sobretudo a de raiz gadameriana. 
do de formação e desenvolvimento integral das potencialidades humanas, racionais, éticas e estéticas. Se o processo educativo fosse pensado somente em termos de ação gestual, ele formaria consciências condicionadas, inibindo, desse modo, o desenvolvimento da criatividade e da autonomia dos envolvidos. A redução da educação a uma ação gestual nos termos pensados por Mead implicaria, simultaneamente, na redução do conceito amplo de pedagogia como estudo a uma técnica de ensino e aprendizagem, restringindo-se a compreender o processo formativo-educacional humano nos limites estritos do procedimento estímulo-reação, sem poder considerar, em última instância, os aspectos oriundos de uma "subjetividade criadora"Talvez pudéssemos prosseguir a analogia aqui e afirmar que a manutenção do processo pedagógico no âmbito gestual provocaria, em última instância, a própria instrumentalização do ensino.

As implicações político-pedagógicas disso para o ideal de formação da consciência cidadã e o exercício de princípios democráticos são enormes. É por isso que Mead, com a preocupação de fortalecer ideais democráticos modernos, volta-se incisivamente contra o reducionismo inerente ao conceito de ser humano provindo tanto da psicologia da consciência como da psicologia experimental. Em sua crítica, estão implicadas razões não só de ordem epistemológica, mas também éticopolítico-pedagógicas, pois, na sua visão, o agir democrático não se coaduna nem com o individualismo oriundo do egoísmo racional baseado em uma ética utilitarista, nem com a mecanicidade rígida do comportamento humano pensada em termos de reflexos condicionados.

De outra parte, o caráter racional inerente ao emprego simbólicosignificativo, quando mobilizado pedagogicamente por meio de processos de aprendizagem, abriria a possibilidade à ação humana de sempre poder começar por si mesma um novo estado e, nesse sentido, de transformar experiências em novos acontecimentos. Isso mostraria, então, um caráter aberto, dinâmico e imprevisível da ação que se choca, por sua vez, com o próprio anseio humano de exercer permanentemente um controle absoluto sobre seus movimentos. Ora, isso se torna uma exigência ao próprio processo pedagógico: se o conteúdo racional da ação brota da capacidade humana de empregar símbolos significantes, tal conteúdo também precisa dar conta da tensão manifesta entre, por um lado, o aspecto criativo e imprevisível da ação humana e, por outro, o anseio de controlar de modo absoluto seus planos e modos de ação.

Por fim, considerando que é na capacidade de produzir identidade comum no emprego de símbolos significantes que reside, segundo Mead, a potencialidade reflexiva da ação humana, é preciso esclarecer o sentido em que tal identidade deve ser buscada para que não aniquile o as- 
pecto espontâneo e criativo da ação em seu nível simbólico-significativo. Isto é, a argumentação de Mead precisa ser questionada aqui pelo próprio conceito de identidade comum: resta saber se tal conceito, conquistado mediante o enfoque evolutivo-comportamentalista de linguagem, não conduz a racionalidade inerente à própria linguagem humana a um outro tipo de reducionismo. $O$ tratamento dessa questão exige que seu argumento mostre a capacidade inerente ao símbolo significante de se constituir efetivamente em elemento de coordenação racional da ação humana. Mas, de acordo com o que foi visto até agora, a coordenação da ação não pode mais ser pensada no contexto de uma teoria da ação introspeccionista e, menos ainda, experimental, mas, sim, simbólica. Portanto, compete à psicologia social, transformada em teoria filosófica da sociedade, pensar o conteúdo da coordenação racional da ação humana por meio de uma teoria simbólica da ação e, para poder executála, não precisa inserir-se, segundo penso, nos trilhos de uma teoria da ação baseada no esquematismo funcional das pretensões de validez dos atos de fala. ${ }^{9}$ Mas esse é já outro tema.

\section{Linguistic shaping of Self and pedagogical action.}

Abstract: This article deals with some aspects of Mead's action theory related to his thesis on the linguistic-social shaping of the Self, by approaching the pedagogical unfoldings which result from it. The article also focuses on showing that the core of Mead's action theory rests on the concept which sees the human being as an acting organism constituted socially through the capacity of employing meaningful gestures and symbols.

Keywords: Action theory. Gestures. Symbol. Self Psychology.

\section{La formation linguistique du Self et l'action pédagogique.}

Résumé: L'article s'occupe de quelques aspects de la théorie de l'action de Mead concernant sa thèse sur la formation lingüistique-sociale du Self, en cherchant à aborder des dédoublements pédagogiques. Il se concentre aussi en démontrer que le centre de sa théorie de l'action repose sur le concept de l'être humain comme organisme agent qui se constitue socialement par le moyen de l'aptitude d'employer des gestes et des symboles signifiants.

Mots-clés: Théorie de l'action. Gestes. Symboles, Signifiant. Psychologie du self. 


\section{Formación lingüistico-social del self y acción pedagógica.}

Resumen: El artículo trata de algunos aspectos de la teoría de la acción de Mead relacionados con su tesis sobre la formación lingüístico-social del Self, buscando abordar desdoblamientos pedagógicos. Se concentra también en enseñar que el núcleo de su teoría de la acción reside en el concepto de ser humano como organismo agente que se constituye socialmente por medio de la capacidad de emplear gestos y símbolos significantes.

Palabras-clave: Teoría de la acción. Gestos. Símbolo. Significante. Psicología del self.

\section{Referências}

Dalbosco, C. A. (2004). G. H. Mead e o problema do modelo reflexivo da autoconsciência: considerações introdutórias. In M.C. Muller \& E. M.Cenci (Orgs.), Ética, política e linguagem: confluências (pp. 155-181). Londrina, PR: CEFIL.

Habermas, J. (1992). Nachmetaphysisches Denken. Philosophische Aufsätze [Pensamento pós-metafísico. Artigos filosóficos]. Frankfurt am Main: Suhrkamp.

Habermas, J. (1995). Theorie des kommunikativen Handelns (Band 1, 4a auf.) [Teoria da ação comunicativa (Vol. 1)]. Frankfurt am Main: Suhrkamp.

Mead, G. H. (1992). Mind, self and society. From the standpoint of a social behaviorist. Chicago: University of Chicago Press.

Smith, P.J. (2005). Do começo da filosofia e outros ensaios. São Paulo:Discurso.

Tugendhat,E.(1997).Selbstbewusstsein und Selbstbestimmung.Sprachanalytische Interpretationen (6a auf.) [Consciência de si e autodeterminação: interpretações anlítico-linguísticas]. Frankfurt am Main:Suhrkamp.

Watson, J.B. (1968). Behaviorismus [Behaviorismo] (L. Kruse,trad.). Köln/Berlin: Kiepenheuer \&Witsch. (Trabalho original publicado em 1930.Título original:Behaviorism). 